\title{
Boundaries matter: Greenhouse gas emission reductions from alternative waste treatment strategies for California's municipal solid waste
}

\author{
Vergara, Sintana E.; Damgaard, Anders; Horvathc, Arpad
}

Published in:

Resources, Conservation and Recycling

Link to article, DOI:

10.1016/j.resconrec.2011.09.011

Publication date:

2011

Link back to DTU Orbit

Citation (APA):

Vergara, S. E., Damgaard, A., \& Horvathc, A. (2011). Boundaries matter: Greenhouse gas emission reductions from alternative waste treatment strategies for California's municipal solid waste. Resources, Conservation and Recycling, 87-97. https://doi.org/10.1016/j.resconrec.2011.09.011

\section{General rights}

Copyright and moral rights for the publications made accessible in the public portal are retained by the authors and/or other copyright owners and it is a condition of accessing publications that users recognise and abide by the legal requirements associated with these rights.

- Users may download and print one copy of any publication from the public portal for the purpose of private study or research.

- You may not further distribute the material or use it for any profit-making activity or commercial gain

- You may freely distribute the URL identifying the publication in the public portal 


\title{
Boundaries Matter: Greenhouse Gas Emission Reductions from Alternative Waste Treatment Strategies for California's Municipal Solid Waste
}

Sintana E. Vergara ${ }^{1}$ Anders Damgaard ${ }^{2}$ and Arpad Horvath ${ }^{3}$

\author{
${ }^{1}$ Energy and Resources Group, \\ University of California, Berkeley. \\ 310 Barrows Hall, Berkeley, CA 94720-3050, USA. \\ sintana@berkeley.edu. Corresponding author. \\ 2 Department of Environmental Engineering, \\ Technical University of Denmark. \\ Miljoevej 113, 2800 Kgs. Lyngby, Denmark. \\ adam@env.dtu.dk \\ ${ }^{3}$ Department of Civil and Environmental Engineering, \\ University of California, Berkeley. \\ 215B McLaughlin Hall, Berkeley, CA 94720-1712, USA. \\ horvath@ce.berkeley.edu
}




\begin{abstract}
How waste is managed - whether as a nuisance to be disposed of, or as a resource to be reused directly affects local and global environmental quality. This analysis explores the GHG benefits of five treatment options for residual municipal solid waste (MSW) in California: Business As Usual (landfilling), Anaerobic Digestion, Incineration, 40\% Reduction, and MaxEnergy (both incineration and anaerobic digestion). Because recycling efforts in California are already strong, this analysis focuses on non-recyclables and asks what else can be done with the material fractions that are currently reaching landfills. Using two different waste LCA models, EASEWASTE (a Danish model) and WARM (a U.S. model), we find that improved biogenic waste management through anaerobic digestion and waste reduction can lead to life-cycle GHG savings when compared to Business As Usual. The magnitude of the benefits depends strongly on a number of model assumptions: the type of electricity displaced by waste-derived energy, how biogenic carbon is counted as a contributor to atmospheric carbon stocks, and the landfill gas collection rate. Assuming that natural gas is displaced by waste-derived energy, that $64 \%$ of landfill gas is collected, and that our system boundary begins when waste is thrown away and ends with disposal or conversion to air emissions, reducing California's residual waste by $40 \%$ can lead to a savings of $6 \mathrm{Mt}$ (million metric tons) of $\mathrm{CO}_{2}$-e per year, and digesting California's biogenic waste could save $0.6 \mathrm{Mt} \mathrm{CO}_{2}$-e per year. Source reduction is the most robust means to mitigate GHG emissions from waste, though either increasing landfill gas capture rates within the current management plan or digesting biogenic waste (and designing landfills to maximize carbon sequestration) provide two other important means for greenhouse gas mitigation from waste management.
\end{abstract}

Keywords: life-cycle assessment, solid waste management, climate change, California, landfill, source reduction, anaerobic digestion. 


\section{Introduction}

\subsection{Goal and Problem Statement}

How waste is managed directly affects local and global environmental quality. Waste transport, treatment and disposal impact local and global air quality and can pollute water and contaminate soil. Waste management can also either aggravate or mitigate climate change (Bogner et al. 2007), an urgent global consequence to which the present discussion is directed. Though there are many important environmental effects of waste management, the focus of this paper is on its climate change implications because the urgency of climate change requires an analysis of the greenhouse gas (GHG) implications of all aspects of our economy, and because there is uncertainty about the contribution of waste-related emissions to climate change. The most recent IPCC report suggests that post-consumer waste is responsible for fewer than 5\% of global GHG emissions, though the IPCC analysis includes only the negative impacts of waste and is not a lifecycle assessment. Importantly, the authors state that this estimate is both highly uncertain and can be mitigated by increasing waste reuse, recycling, and energy utilization (Bogner et al. 2007).

A steady increase in global waste production provides both a problem - how to manage this waste without negatively impacting the environment - and an opportunity, as more waste can be combined with technologies and policies that can allow for improved waste reuse. This paper looks for such opportunities by analyzing the GHG emissions from several alternatives for the treatment of municipal solid waste (MSW) in the United States, a nation that is one of the highest waste producers in the world. Because local conditions determine the political feasibility and the environmental impacts of differing waste management scenarios, this analysis is a case study in a place that has taken bold action on several environmental fronts (Hanemann 2008): California. It has the largest economy of all the states, and is a major producer of MSW. Due to these factors, it is a place where radical new waste management solutions may be implemented, and the case study serves as an illustration of the types of mitigation possibilities available for high wasteproducing regions.

This analysis asks what else can be done with the material fractions that are currently reaching landfills; these materials represent lost opportunities for resource recovery. Because the recycling efforts in California are already strong and the low-hanging fruit of recyclables have already been picked, the assessment focuses on material fractions that can be effectively managed through new means: either with alternative technologies or behavioral change.

The aims of this paper are two-fold: to help guide solid waste management policy in California by analyzing waste treatment scenarios for their climate mitigation potential, and to explore uncertainties in solid waste life-cycle assessment (LCA) methodology used to analyze alternative management strategies. This study is an opportunity to examine the roles that alternative technologies and consumer behavioral change could play in reducing GHG emissions from California's waste, and also how modeling choices affect the final results of the assessment. The paper applies life-cycle thinking to look critically at alternative waste management plans, as suggested by the EU waste framework directive (Council of the European Union 2008). This is the first study that compares different treatment options for California's waste that includes both technological and behavioral solutions, and is the first analysis that uses the Danish model, EASEWASTE (Kirkeby et al. 2006), to analyze waste management in the United States. This model's results are compared to those obtained through WARM, the US Environmental Protection Agency's model (2006). 


\subsection{Background}

Life-cycle assessment is "the examination, identification, and evaluation of the relevant environmental implications of a material, process, product or system across its lifespan from creation to waste, or preferably to re-creation in the same or another useful form” (Graedel 1998). As such, LCA has emerged as an essential method to quantify the environmental benefits and drawbacks of solid waste management options (Bogner et al. 2007; McDougall et al. 2001; Council of European Union 2008). In addition to following the standard guidelines of LCA outlined by the ISO 14040 (ISO, 2006a; ISO 2006b), recent waste LCA analyses (those that ask: "What should we do with our waste?") have generally adopted a system boundary that includes the waste management system, from the moment of disposal until conversion to an emission or a reusable product (Finnveden 1999). Importantly, however, product manufacture, distribution, and use are outside the system boundaries for these analyses (Gentil et al. 2009b).

Waste LCAs have also embraced a "zero burden assumption," which takes the waste managed by the system as a given, and ignores the upstream environmental burdens associated with that waste, implicitly attributing those burdens to the products themselves and not the waste per se (McDougall 2001; Ekvall et al. 2007). Additionally, biogenic carbon from waste is widely assumed to have no Global Warming Potential (GWP), since its carbon was recently sequestered from the atmosphere (Barton et al. 2008; Christensen et al. 2009; Gentil et al. 2009a; Rabl et al. 2007). But the former two assumptions are not consistent; if waste carries with it no environmental burdens, then it should not carry with it any environmental benefits either. Taking waste as a given at the point of disposal, waste managers must determine how to minimize the emission of greenhouse gases to the atmosphere going forward; the source of those gases do not matter. Past work (Christensen et al. 2009) has found that, from a decision-making perspective, counting or not counting carbon dioxide from biogenic waste can be equivalent (if biogenic carbon dioxide count as +1 , and stored carbon as 0 ; or biogenic as 0 and stored carbon dioxide as -1). Many waste LCA methodologies state that biogenic emissions should be reported even when given a GWP of zero (Gentil et al. 2009a), but this is often not done in practice. This analysis explores whether counting and characterizing biogenic carbon emissions can alter the results of a waste LCA.

Another major methodological choice that LCA waste modelers make is whether to perform an attributional or a consequential assessment, where the former describes the physical flows to and from the system studied (e.g., Stokes and Horvath 2011), and the latter attempts to describe how physical flows, including those outside the physical system, will change in response to changes in the life-cycle (Ekvall and Weidema 2004). Though both attributional and consequential LCA are inherently uncertain, this paper's goal is to understand how the waste management system will interact and affect the environment surrounding it. In striving towards a consequential analysis, this work utilizes marginal electricity data both for the energy used by waste treatment and for the electricity displaced by waste-derived energy.

\section{Methods}

\section{1 Scope and functional unit}

The boundaries of this study are both theoretical and geographical. First, the study compares the downstream environmental benefits and impacts of the management of MSW, not the generation or production of that waste. Figure 1 provides a schematic of the system boundary used, which 
begins with its collection at the curb, and ends with its conversion to an emission or inert substance. This system has very important interactions with the outside world, namely in construction of each facility used, emissions to the environment, and in energy use and production. The spatial boundary is the California border, including only waste that is handled within the state. The state exports a small fraction ( 1\%) of its disposed waste (CalRecycle, 2010); this fraction is not included in the analysis.

The functional unit for this analysis is 1 tonne of MSW produced in one year, as collected curbside. The composition of the waste considered in the study is that of California's residential and commercial solid waste in 2004 that was landfilled. Importantly, 48\% of the waste generated has been removed from the waste stream, to be recycled, composted, or reused (CIWMB 2008). The study analyzes the net GHG emissions associated with the following waste management scenarios:

(1) Business As Usual (BAU), the current management plan, in which all that is currently landfilled continues to be landfilled, and 64\% of landfill gas (LFG) is collected during the active collection phase (based on median value for California landfill gas collection, Themelis and Ulloa (2007)).

(2) $\mathbf{4 0} \%$ Reduction, in which $40 \%$ less waste, across all residual material fractions, is generated by Californians, but is managed like BAU. This source reduction can reflect a reduction in overall consumption (fewer purchases, same waste rate), or a reduction in what is thrown away (same consumption, smaller waste rate).

(3) Incineration, in which inorganic non-combustible waste is sorted from combustible waste in a MRF and sent directly to a landfill, the energy-rich, combustible fraction of MSW (e.g., plastics and paper) is co-combusted with $20 \%$ of the biogenic waste (e.g., food waste) in an incinerator, producing electricity, and the rest of the waste is sent to the landfill.

(4) Anaerobic Digestion (AD), in which biogenic waste (mostly food waste, not including paper) is digested and methane is recovered and burned for electricity production, and the rest of waste is sent to the landfill.

(5) Maximization of Waste-to-Energy (MaxEnergy), in which biogenic waste is digested and methane is recovered and utilized, inorganic non-combustible waste is sorted from combustible waste in a MRF and sent directly to a landfill, and the inorganic combustible waste is incinerated to produce electricity.

The mass flows for each scenario, as well as the assumed distances that waste travels between treatment steps, are illustrated in Figure 2:

The scenarios explored represent feasible changes to use California's waste as a resource. Business as Usual (BAU) describes the waste management system as it is currently, and thus is the baseline to which all other scenarios are compared. Scenario 2, 40\% Reduction, describes a significant reduction in residual waste generation, but no change in the management of waste. Despite California's success in achieving 50\% waste diversion - that is, keeping 50\% of California's residual waste out of landfills - source reduction (decreasing the mass of waste produced by simply throwing less away, either through increasing reuse or decreasing consumption) is not currently being considered as a method to achieve the GHG reductions called for by California's Assembly Bill 32 (CARB 2008). We propose a $40 \%$ source reduction - a reduction in the amount of waste thrown away by Californians - as a feasible and potentially 
robust means of reducing GHG emissions from the waste sector. Scenario 3 explores anaerobic digestion of organic wastes; this technology is cited by the California Air Resources Board as being capable of reducing GHG emissions state-wide by $2 \mathrm{Mt} \mathrm{CO}_{2}$-equivalents per year. This analysis independently assesses the emission reductions that can theoretically be achieved by digesting biogenic MSW. Finally, two scenarios analyze whether incineration of waste can play a role in reducing GHG emissions; one calls for the separation and incineration (with energy production) of inorganic and energy-rich waste components, and the other combines incineration with digestion of biogenic waste. Historically unpopular in California but widely used in Europe in waste management, incineration is not cited in the AB32 Scoping Plan as a strategy for reducing emissions from waste (CARB 2008).

To understand the environmental impact of these different waste diversion schemes, two models are used. The first is EASEWASTE, a model developed by the Technical University of Denmark, and fully specified in Kirkeby et al. (2006). This model is flexible, allowing the user to input values for every stage of the waste management process, and also contains empirical data and process models for the performance of solid waste transport and treatment technologies (e.g., trucks, material recovery facilities, landfills, digesters, incinerators). Anaerobic digestion and incineration are considered as potential technologies for California's waste because they have been applied broadly and successfully for solid waste treatment, most commonly in Europe, and thus can be feasibly and rapidly deployed.

The scenarios were also modeled using the Waste Reduction Model (WARM) (US EPA 2006), created by the United States Environmental Protection Agency, to see how the GHG benefits estimated differ by the model used. While WARM has been used broadly in US-based analyses, EASEWASTE has not yet been used in a US-context.

\subsection{Data and Modeling Assumptions}

This analysis relies on data from the California waste management system, as well as from its energy system. The main input to our model is the quantity and composition of California's disposed municipal solid waste, as collected curbside, over the course of one year. The "diverted waste" - to composting or recycling facilities - has already been removed. Our analysis focuses on this disposed fraction of waste - the waste that is currently being sent to landfills - to explore what else (other than increasing material recycling) can be done to reduce GHG emissions with California's waste once it is thrown to the curb. The characteristics of California's residential and commercial MSW are shown graphically in Figure 3 (CIWMB 2004). The figure shows that 70\% of the MSW that is currently disposed can be used for energy production: $34 \%$ of waste is “organic,” defined by California’s Integrated Waste Management Board as food waste, yard waste, textiles, and manure (we refer to this fraction as “biogenic”), $25 \%$ is paper, and $11 \%$ is plastic. This analysis excludes self-hauled waste. In order to input California's waste into EASEWASTE, the 66 material fractions specified in CIWMB (2004) were converted into the 48 material fractions used in EASEWASTE, and the 34 material fractions used in WARM.

Distances traveled by waste collection vehicles are modeled after average values for Alameda County, California (Carr 2008; Padia 2010) and are shown in Figure 2. Since most of California's population resides in one of two metropolises (the San Francisco Bay Area and the Los Angeles basin), waste transport in the state can be modeled as waste transport in an urban county. This assumption is strengthened by the exclusion in the analysis of all self-hauled waste; this waste is 
likely to come from rural regions that are not served by municipal haulers. When using the EASEWASTE model, landfill behavior is modeled after Manfredi and Christensen (2008), and follows a generic landfill process model - $10 \mathrm{~m}$ deep and 100 year timeframe - found in EASEWASTE. Landfill gas capture data come from Themelis and Ulloa (2007), who provide empirical California landfill gas capture rates. Incinerator emissions and operation data are borrowed from an existing dataset on a conventional grate furnace incinerator in the Danish municipality of Aarhus, and anaerobic digester performance data come from a generic digester model within EASEWASTE. The life-cycle impacts of the incinerator are described fully in Riber et al. (2008).

For the WARM model, the user inputs are fewer. We specify the waste composition for the baseline and alternative scenario, define an overall distance traveled by waste, and select the landfill gas capture rate of the landfills used, which we also take from Themelis and Ulloa (2007). Other assumptions in the WARM model are described in US EPA (2006).

All scenarios specify energy recovery from waste. California's electricity baseload demand is met by nuclear power, hydropower, natural gas and other renewables (McCarthy et al. 2008). The technologies that ramp on and off according to demand include system imports and natural gas technologies (natural gas steam turbine, natural gas combustion turbine, natural gas combined cycle and system imports). In our analysis, we assume that any energy produced displaces the marginal unit of electricity in California, which almost always comes from natural gas combustion (Marnay et al. 2002, Stokes and Horvath 2009). Landfill gas collection from landfills for all scenarios begins 2 years after landfill construction, capturing 64\% of gas produced for 35 years. Of the gas collected, $70 \%$ is used for electricity production and $30 \%$ is flared (Themelis and Ulloa 2007). After 35 years, gas produced in the landfill is vented, since at that point the concentration of methane is usually too low for combustion.

\section{Results and Discussion}

\subsection{Emissions from Waste Management Strategies in California, assuming natural gas as marginal electricity source}

All scenarios are compared to "Business As Usual” (BAU) to see if alternative scenarios are preferable to how waste is currently being handled, from a GHG management perspective. Figure 4, calculated using EASEWASTE, shows that collection and transportation contribute modestly to the life-cycle greenhouse gas emissions from each scenario, as compared to "treatment, recovery, and disposal.” Even though emissions from collection and transportation are much smaller than the emissions from waste treatment, these emissions still total about half a million tonnes of $\mathrm{CO}_{2}$-equivalent $\left(\mathrm{CO}_{2}\right.$-e), corresponding to about $10 \%$ of the total emissions savings from the transportation sector called for in AB32, the Global Warming Solutions Act of 2006 that established a GHG reductions goal as law. The waste reduction scenario ( $40 \%$ reduction) boasts GHG reductions from collection and transportation alone that would achieve $4 \%$ of the savings called for from California's transportation sector (CARB 2008).

Waste treatment - the category that includes all the processing of waste, including sorting, anaerobic digestion, incineration, and landfilling - contributes most to the GHG emissions from waste and to the variation between scenarios. Net GHG emissions vary greatly between scenarios, and two scenarios - Source Reduction and Anaerobic Digestion - achieve net GHG savings from Business As Usual. Focusing solely on California’s biogenic, digestable waste and 
digesting it to produce electricity can lead to a GHG reduction of $0.6 \mathrm{Mt} \mathrm{CO}_{2}$-e as compared to BAU; this estimate is slightly lower than CARB's estimate of $2 \mathrm{Mt} \mathrm{CO}_{2}$-e from digestion (CARB 2008). Finally, even though 40\% Reduction only receives credit for GHG savings that occur downstream of the materials becoming waste - the upstream savings lie outside the scope of this analysis (Gentil et. al 2009a) - the scenario has the lowest net GHG emissions. If Californians produced 40\% less residual waste, GHG emissions from waste management would decrease by 6 $\mathrm{Mt} \mathrm{CO}_{2}$-e. Implementing either Incineration or MaxEnergy as waste management strategies would emit an additional $3 \mathrm{Mt} \mathrm{CO}_{2}$-e to the atmosphere.

Figure 4 is computed using the broadly accepted assumption about biogenic carbon emissions: that they do not represent a net contribution of GHGs to the atmosphere. The argument is that this carbon was recently sequestered by biogenic matter, so its subsequent release does not represent an addition of carbon to the atmospheric stock.

\subsection{Sensitivity Analyses}

\subsubsection{Landfill behavior}

Figure 4 shows that there are methods to substantially reduce GHG emissions from California's waste management. To understand the robustness of these results, four sensitivity analyses are undertaken: on how the results would differ if biogenic carbon emissions were counted as contributing to global warming, on how sensitive the results are to assumptions about landfill gas collection rates, on how the selection of an LCA model can affect GHG emission results, and on the importance of the modeler's assumption of what sort of electricity is displaced. Understanding how the results are altered by these assumptions will allow for an understanding of the conditions under which GHG reductions can be achieved.

Figure 5 shows how the estimated GHG emissions from BAU change with varying assumptions about landfill behavior by comparing BAU to two other bounding scenarios: LFG16, in which $16 \%$ of generated landfill gas is collected over 35 years for electricity production, and LFG80, in which the landfill gas recovery rate is $80 \%$ over 35 years. The variation between the three landfill scenarios results in life-cycle GHG estimates that differ from the average LFG collection rate by a factor of 1.5. The reason for this large difference is that the uncollected methane is a more potent greenhouse gas than carbon dioxide, and the higher collection rates mean a larger amount of methane converted to $\mathrm{CO}_{2}$. Assumptions about landfill performance can therefore greatly impact the results of waste life-cycle analyses.

\subsubsection{Electricity Displacement}

All scenarios shown in the above figures assume that any electricity produced from waste displaces the marginal source of electricity in California, natural gas (combined cycle). To explore how sensitive the results are to this assumption, Figure 6 shows the changes in net GHG emissions for each scenario if the waste-derived energy were instead displacing coal or wind power, which represent extremes of carbon intensity for electricity production, and thus are bounding cases. Coal may be displaced by waste electricity in the short-run in places that rely heavily on coal-fired power plants, and wind power may be displaced by waste in areas that have adopted a policy like a Renewable Portfolio Standard, requiring a certain percentage of electricity to come from renewable sources. In this case, entry of a new renewable source to the grid would simply knock off another, more expensive, low-carbon source of electricity. It is unlikely that the entry of a large amount of electricity to the grid would result in the displacement of only wind 
power, however, given its intermittency. Figure 7 shows how the life-cycle GHG emission results for each scenario would change if the displaced electricity were altered.

The distance between bounding cases (triangles to circles) grow larger as more electricity is derived from waste. This makes intuitive sense: the more coal that is displaced, the larger the GHG benefit, and the more wind that is displaced, the larger the GHG burden. Thus for the case of LFG16 (BAU but with very low landfill gas collection), the three displacement scenarios are roughly equivalent. With higher gas collection (in the case of LFG80), the difference between scenarios grows.

For the high energy producing scenarios, Incineration and MaxEnergy, the selection of electricity type displaced greatly affects the estimate for life-cycle GHG emissions. In fact, if MaxEnergy's waste electricity displaces coal, it becomes one of the lowest emitting scenarios; if its electricity displaces wind, it is the highest emitting scenario. Similarly, for Incineration, when its electricity replaces coal it is among the lowest emitting scenarios, and when it instead knocks wind off the grid, it is among the highest emitting scenarios. The life-cycle emissions associated with each scenario varies strongly with the assumed electricity displaced; this assumption alters the order of preferred scenarios, and shows that it is extremely important to understand that changes to waste management impact the energy system and vice versa. Understanding the nexus between the waste and energy systems is crucial to understanding the environmental impacts to changes in waste management programs.

\subsubsection{Variation between models}

We compare our results using EASEWASTE with those obtained from running the scenarios using the US-based model, WARM. Unfortunately, only a subset of the scenarios can be analyzed using WARM, because the program does not consider anaerobic digestion as a waste treatment technology. Figure 7 shows the emissions predicted for three scenarios using WARM, and the variation in the estimates according to the assumed landfill gas capture rate.

Though both models predict that $40 \%$ Source Reduction is the scenario that emits fewest greenhouse gases to the atmosphere, WARM finds that, unlike EASEWASTE, incineration of waste has roughly equivalent GHG emissions as BAU for the average landfill gas collection scenario. Figure 7 also shows that reducing the production of waste leads to major GHG savings (approximately $40 \mathrm{Mt} \mathrm{CO}_{2}$-e for the average landfill gas collection scenario). The landfill gas

collection rate is responsible for variation in life-cycle GHG emissions over a factor of 1.1 for the source reduction scenario, 6 for BAU and 2 for incineration. The variation is greatest for the $\mathrm{BAU}$ case because it is the case for which the greatest amount of biodegradable waste is arriving to the landfill, and its subsequent methane production has a very high GWP.

There are several sources of the variation between models. The WARM model has far fewer user inputs - only waste composition, travel distances, and LFG collection rates - than

EASEWASTE, a model in which every technological process and distance is defined by the user. A very important source of variation comes from assumptions about electricity generation. The WARM model does not allow the user to define the source of electricity used in waste treatment processes, nor the type of electricity displaced by electricity production from waste. This model assumes that the electricity produced and avoided is the average fossil-based electricity in the United States - roughly $45 \%$ more carbon intensive than the average electricity mix in the U.S. 
(US EPA 2006) - which does not represent the actual grid in any region. The emissions from this average fossil electricity mix falls somewhere between coal and natural gas power in its life-cycle emissions, and the exact mix determines where on the vertical axis of Figure 6 the emissions from each scenario fall. This mix can also affect which scenarios look better or worse, from a GHG perspective, as shown in Figure 6. The difference in the type of electricity displaced between the two models contributes to the differences in the emissions reductions estimated by each.

WARM's estimate of the emissions from 40\% Reduction is much lower than is EASEWASTE`s because of a difference in the system boundary definition between the two models. In WARM, the savings from $40 \%$ Reduction include upstream avoided production, so the scenario gets credited with emission reductions from all the products that never need to be manufactured when people consume less. These avoided emissions are much greater than the direct emissions that would have been released if the waste had been generated. This avoided production falls outside of the system boundary for EASEWASTE, so the emission reductions from $40 \%$ Reduction in this model are smaller.

\subsubsection{Counting biogenic carbon emissions}

Figure 8 shows the life-cycle GHG emissions if biogenic carbon releases from the waste management system are counted as a contributor to Global Warming. As discussed previously, waste LCAs often assume that waste entering the system carries with it no environmental burdens from its production and consumption. However, it is also widely assumed that the waste does carry with it some benefit: carbon from waste of biogenic origin is assumed to be carbon-neutral. While there are conditions in which these two assumptions can be reconciled (Christensen et al. 2009), they can also lead to a bias towards releasing biogenic carbon (Searchinger et al. 2009).

In agreement with Gentil et al. (2009a), Figure 8 shows that counting the biogenic carbon emissions does not change the order of preferred scenarios, but does change the magnitude of the emissions associated with each scenario. In all previous figures, biogenic releases were given a value of 0 , and stored carbon was given a value of -1 ; here in Figure 8 , biogenic releases are counted as 1 , and stored carbon as 0 . Figure 8 compares the ordering of scenarios for the cases under the two biogenic carbon counting schemes. In ascending order, $40 \%$ Reduction is the lowest-emitting scenario, followed by LFG80, Anaerobic Digestion, and BAU. Incineration and MaxEnergy follow, and are about equivalent, and LFG16 has the greatest GHG emissions. The scenarios that produce the most energy, under the expected case in which natural gas is displaced, are among the highest emitters. This is largely due to the fact that paper is burned in the two incineration scenarios (Incineration and MaxEnergy), resulting in a one-time pulse of biogenic carbon contained in the paper. In the other scenarios, the paper in the waste stream is landfilled, and much of that carbon (bound in lignin) remains sequestered in the landfill. In comparing the scenarios in which biogenic carbon is counted as contributing to Global Warming to those in which it is not, a small discrepancy is noted: MaxEnergy and Incineration switched places in the scenario ranking between the two accounting methods. This difference can be attributed to model-based error. In EASEWASTE, the calculations for how much methane is generated from a fraction of waste and the biogenic carbon content for a fraction of waste are based on empirical measurements, and these measurements are not always derived from the same waste sample. That these two parameters are therefore not $100 \%$ correlated can lead to small changes in the carbon emissions estimated from Municipal Solid Waste, and can lead to variation in the emissions. 
From a GHG perspective, two scenarios are preferable to BAU: 40\% Reduction and Anaerobic Digestion. Source reduction emerges as the preferred waste management scenario; it results in the lowest emission of GHGs and also provides environmental benefits outside of the waste management system. In this scenario, additional carbon is sequestered outside of the waste management system, due to natural resources that are never extracted, and the products that are never produced. This decreased production allows that biomass to be used for other purposes, both anthropocentric (e.g., energy) (McKone et al. 2011) and not (e.g., land preservation).

The use of waste as an energy resource should focus upon alternative organic waste management. Digesting biogenic waste in California leads to GHG benefits as compared to BAU; this scenario maximizes the extraction and utilization of the methane that is released from the waste, and allows the landfill to function solely as a carbon sequestration site. Though incineration for electricity production in California may be preferable to the use of fossil fuels when comparing the carbon footprint of energy sources, incineration is not preferable when we are comparing alternative fates for the waste we produce.

There are additional possible benefits to separating and treating organic waste. First, the emissions associated with anaerobic digestion can be reduced further by drying the digestate before it is transported to the landfill. The digestate can also be returned to farmland, thereby recycling valuable nutrients $(\mathrm{N}, \mathrm{P}, \mathrm{K})$; this may become especially important in the future when phosphorus is likely to be a limited resource. Finally, separating organic waste can improve the recycling rates for other products; if paper and plastics are not mixed with biodegradable waste, they can be more easily recovered. Both digesting organic waste and improving landfill gas capture rates can be done using already existing infrastructure. Conventional wastewater treatment plants already have anaerobic digesters for liquid wastes (Stokes and Horvath 2010), and co-digestion of liquid and solid wastes has been shown to increase methane generation (Edelmann 2000; Sosnowski et al 2008), though the mixing of liquid and solid wastes brings on added risks of pathogens, and can limit the possibilities for land application of the waste (Murray et al. 2008).

Business As Usual functions mostly as a carbon sequestration project, provided that landfill gas capture is sufficiently high, because a large fraction of disposed waste in California is paper, which resists degradation. Landfill performance is a decisive variable: if at least $64 \%$ of landfill gas is captured, then it is among the best waste management strategies from a GHG perspective. However, lower rates of landfill gas collection (e.g., 16\%) result in large emissions of methane, which override any benefits in sequestration, and result in the highest GHG emissions of all scenarios considered. Improving landfill gas capture in already-existing landfills provides an opportunity to decrease waste-related GHG emissions.

\section{Uncertainty in results}

The uncertainty in the waste LCA results - the fact that a couple of parameter variations can alter the order of preferred scenarios - highlights the importance of sensitivity analyses in waste LCAs. This paper shows that both landfill gas collection rates and energy displacement strongly impact the estimated emissions from waste treatment and the ranking of waste treatment scenarios, and that biogenic accounting schemes affect the magnitude of the estimate. The model used to analyze waste treatment scenarios also impacts their estimated GHG emissions; this 
analysis showed that EASEWASTE and WARM differ in their assessments, largely because of a difference in their system boundaries.

How one counts biogenic carbon does not affect the rank-ordering of scenarios (Christensen et. al 2009) and is ultimately a question of time scale. At geologic time-scales, all carbon is "biogenic," having been relatively recently sequestered. At very short time-scales, all carbon is fossil, having been sequestered relatively long ago. Waste LCA analyses normally consider a time period of 100 years, and comparatively, biogenic waste in MSW has a very short carbon cycle, and thus the common assumption of neutrality of its emissions is reasonable. It is important to realize that the accounting scheme is another source of variation in the results of a waste LCA; even if it does not impact the ordering of scenarios, it does impact the estimate of the magnitude of the emitted GHGs, and thus impacts how using waste as an energy resource compares to using other energy resources. As such, analyses should also consider results under both carbon accounting schemes: one in which biogenic releases are counted as positive emissions, and one in which these emissions are carbon-neutral, but carbon storage is given a negative atmospheric carbon value. Though both accounting schemes are coherent and equivalent in a waste LCA decision-making context, counting carbon emissions from biogenic carbon makes methodological sense; if a decision maker is choosing how to treat our waste, all that happened to that waste before it was thrown away is irrelevant. All of its environmental burdens and benefits upstream of curbside disposal do not affect the decision of what do to with an existing tonne of waste; its downstream carbon flows determine the preferable waste treatment option.

Analyses should also consider the energy context of any waste-to-energy project. High energyproducing waste decisions can either be net carbon mitigators or net carbon contributors depending on the source of electricity they are displacing. The most GHG mitigation will occur where the marginal source of electricity is fossil based (e.g., coal), and the least will occur where the marginal source is low-carbon (e.g., wind) (Pacca and Horvath 2002). Presenting these key sources of variation is essential to understanding the robustness of waste LCA results, and to guiding decision-makers to make effective decisions.

\section{Conclusions and policy recommendations}

Although there are various effective alternatives for reducing the GHG emissions from California's solid waste management, the amount of GHG reduction obtained from pursuing alternative treatment scenarios depends strongly on the efficiency of landfill gas collection rate, the electricity displaced by waste electricity, and how biogenic carbon emissions are accounted for. Our estimate of these reductions is also affected by the model used. The former sources of variation can change the order of preferred treatment scenarios. Assuming that natural gas is displaced by waste-derived electricity, as is most likely the case, then only $40 \%$ Reduction and Anaerobic Digestion achieve GHG savings when compared to the Business As Usual case. The same is true if wind power were displaced. This is an unlikely scenario, however, unless a tough Renewable Portfolio Standard is set for the state and it is already flooded with renewables. But if coal is displaced by waste derived-electricity, all scenarios except for LFG16 outperform BAU. The landfill gas collection rate determines whether Business As Usual is among the best or is the worst alternative for waste treatment. The manner in which biogenic carbon is counted does not affect the order of preferred scenarios, but does affect the magnitude of the GHG emissions (or savings) associated with each waste management plan. Future waste analyses should consider results under both carbon accounting schemes (biogenic releases as positive emissions, or 
biogenic emissions as carbon-neutral but carbon storage given a negative atmospheric carbon value), and also consider the energy context of any new waste management plan. Finally, model selection should be considered when analyzing results. The two models used in our analysis, WARM and EASEWASTE, differ in system boundary selection, in assumptions about the type of electricity used and displaced by waste management, and in which aspects of the waste management system can be specified by the user. These inherent differences between models can drive differences between scenarios analyzed.

Given the uncertainties in electricity displacement, and in landfill gas collection over the long life span of a landfill, reducing the amount of waste that is produced in California - either by consuming less or wasting less- is the most robust greenhouse gas abating option; its emissions are certainly lower than those of the business as usual case, and its emissions do not vary strongly with landfill behavior or the type of electricity displaced. Further, reducing waste has upstream benefits outside of the waste management system that are not captured by most waste LCA analyses (though they are estimated in the WARM model). The challenge in source reduction is not in capital investment, as it may be for other scenarios, but in incentivizing and achieving long-term behavior change among consumers. Ensuring high landfill gas capture rates within the current management plan, or digesting biogenic waste and designing landfills to maximize carbon sequestration provide two effective alternatives for greenhouse gas mitigation from waste management.

Importantly, carbon emissions are not the only measure that should determine our waste management strategy. This analysis focuses on the climate implications of how we manage our waste because it is an important piece of how waste affects our environment. However, how waste is managed also directly affects air quality, resource depletion, public health, and ecological health; the economic and social costs of waste management alternatives also play an important role in the selection of the optimal waste policy. There is likely no single metric for waste practices that applies everywhere and always; local landfill conditions and practices affect effective carbon sequestration, and public perception of waste technologies and of community priorities determine what kinds of treatment are acceptable. Depending on local priorities, it may be preferable in one community to burn natural gas and sequester fossil plastics in a landfill to minimize processing and handling costs and local air pollution, and another community may choose instead to burn plastics, in order to avoid construction of a new landfill in an ecologically sensitive area and to have a source of domestic fuel. Decisions about how to handle waste depend both on the question asked - whether we ask how to best handle waste or from which energy source to create electricity affects the result - and on the priorities of the community affected by the answer.

\subsection{Policy recommendations}

In order to realize the potential gains from source reduction and from anaerobic digestion of organic waste, strategies must be implemented to lower the barriers to the adoption of these measures. Waste reduction involves long-term behavior change. Educational outreach can help consumers realize the impacts of their waste production. Creating incentives for consumers to produce less waste is more likely to have an impact. Such incentives can include taxing waste production - either directly through Pay-As-You-Throw programs, whereby consumers pay for their waste disposal according to the amount they produce, or by increasing the tipping fees at landfills - or paying consumers to separate their green waste. 
Diverting organic waste from landfills can provide climate benefits through two avenues: fuel displacement and carbon sequestration. The diverted waste can be digested as an energy resource, displacing more carbon-intensive fuels, and without the organic waste, the landfill will become drier and more able to serve as a carbon sequestration site. But there are many barriers facing the implementation of anaerobic digestion of organic waste in California. The obstacles that wastewater or waste treatment facilities face in generating electricity from biogas are similar to those faced by farms seeking to digesting their own waste. These obstacles include high capital costs, finding appropriate financing, uncertainty about the value of produced electricity, high transaction costs in connecting to the grid, and a lack of incentive to produce electricity beyond what the waste producer consumes (Rickerson et al. 2008, Gloy and Dressler 2010, Dowds 2009). This disincentive is produced by California's net metering policy, which allows small generators to offset their own electricity costs by providing electricity to the grid, but does not compensate them for any electricity produced beyond what they consume. An additional barrier has been placed by state utilities, who have set a cap of $50 \mathrm{MW}$ on the total allowable digester capacity in the state (Rickerson et al. 2008). This cap both discourages the construction of new facilities and can force digesters to flare excess gas produced instead of utilizing it.

Some of these barriers are being addressed by recent policy measures, but more could be done to encourage electricity generation from waste. Two policies in California make it easier for small digesters to supply the grid with waste-derived electricity. The first is the Renewable Portfolio Standard, stipulating that 33\% of California's electricity must be generated from renewable sources by 2020. Because biogas is eligible as a renewable fuel, this provides incentives for small generators to compete to fulfill the renewable requirement. The second is California Assembly Bill 1969, which obligated the California Public Utilities Commission (CPUC) to create a "standard offer contract," a contract stipulating a fixed-price from which utilities may purchase electricity from small renewable generators (Rickerson et al. 2008). The bill lowers the transaction costs for small biogas producers by creating a standard mechanism for the exchange between generators and the utilities, and also provides an alternative to the net-metering structure. Germany uses a similar policy, a feed-in tariff, to pay producers a premium for their renewable energy generation, thus providing an incentive for investment. In California, however, the electricity produced under this mechanism is sold to utilities at a Market Price Referent (MPR), a price set annually by the CPUC at the avoided cost of generation, meaning the price the utility would have paid for electricity from a new natural gas-fired power plant, if that renewable source did not exist (Rickerson et al. 2008). Importantly, this price does take into account the temporal value of electricity, differentiating between the price during peak and non-peak times. Also importantly, no such feed-in tariff contracts have yet been awarded because the retail rates in California are almost always higher than the feed-in tariff rate, so most generators prefer to use net metering to offset their own electricity demand (Rickerson et al. 2008, Gloy and Dressler 2010).

Because biogas production has not increased in response to these policies, it is clear that more is needed to incentivize biogas producers' entrance to the electricity market. Specific policies could spur investment in anaerobic digestion by:

- helping to financing capital costs by providing special loans or subsidies for construction of digesters (Gloy and Dressler 2010) 
- encouraging energy production by altering the net metering policy so that utilities pay for excess energy delivered (CEC 2009)

- encouraging organic waste diversion by increasing the tipping fee at landfills,

- providing a method to value the positive environmental externalities of producing energy from biogas (e.g., carbon taxes, renewable energy premiums; CEC 2009).

Digester operations themselves could invest in storage facilities that would allow them to operate as peaker plants, only selling to the grid at the most valuable times (CEC 2009), cooperating with other organic waste producers to implement co-digestion and thus benefit from the resulting economies of scale and giving them more negotiating power with the utility, or by selling coproducts (e.g., fertilizer, animal bedding material; CEC 2009, Dowds 2009).

For electricity to be produced in large quantities from food waste, a feedstock whose production is assured and whose methane-generating capacity must be well-managed, one or more of the preceding policy measures must be enacted by California.

\section{Acknowledgements}

We thank Michael O'Hare for his helpful comments on earlier drafts, and the graphical department at the Technical University of Denmark for their visual editing of the figures. 


\section{References}

Barton JR, Issaias I, Stentiford E I. Carbon - making the right choice for waste management in developing countries. Waste Manage 2008; 28(4): 690-698. doi:10.1016/j.wasman.2007.09.033.

Bogner, J, Abdelrafie Ahmed M, Diaz C, Faaij A, Gao Q, Hashimoto S, Mareckova K, Pipatti R, Zhang T. Waste Management. In: Metz B, Davidson OR, Bosch PR, Dave R, Meyer LA, editors. Climate Change 2007: Mitigation. Contribution of Working Group III to the Fourth Assessment Report of the Intergovernmental Panel on Climate Change. Cambridge, United Kingdom and New York, NY, USA: Cambridge University Press, 2007.

California Air Resources Board. 2008. Scoping Plan. Accessed June 11, 2010:

<http://www.arb.ca.gov/cc/scopingplan/scopingplan.htm.>

California Energy Commission. Economic study of bioenergy production from digesters at California Dairies. October 2009. CEC-500•2009•058.

California Integrated Waste Management Board (2004). Statewide Waste Characterization Study. Accessed November 20, 2010: <www.ciwmb.ca.gov/Publications/LocalAsst/34004005.pdf>

California Integrated Waste Management Board (now CalRecycle)

--(a) 2008. Statewide Waste Generated, Diverted, and Disposed. Accessed October 24, 2008:

< www.ciwmb.ca.gov/LGCentral/Rates/Graphs/RateTable.htm>

--(b) 2004. Statewide Waste Characterization Study. Accessed October 24, 2008 :

$<$ www.ciwmb.ca.gov/Publications/LocalAsst/34004005.pdf>

--(c) 2010. Annual California Solid Waste Disposal. Export and Import Tonnage, Statewide

Totals 1995-2008. Accessed May 11, 2010:

<www.calrecycle.ca.gov/LGCENTRAL/Reports/DRS/Statewide/SWExIm.aspx>

Carr, Nancy. 2008. Personal Communication. Senior Integrated Waste Management Specialist, Statewide Technical and Analytical Resources Division, California Integrated Waste Management Board.

Christensen TH, Gentil E, Boldrin A, Larsen A, Weidema B, Hauschild M. C balance, carbon dioxide emissions and global warming potentials. Waste Manag Res 2009 Nov; 27(8):707-15. doi:10.1177/0734242X08096304

Council of the European Union. 2008. "Directive 2008/98/EC of the European Parliament and of the Councilof 19 November 2008 on waste and repealing certain Directives.” Accessed May 12, 2010. Available from:

<eurlex.europa.eu/LexUriServ/LexUriServ.do?uri=CELEX:32008L0098:EN:NOT.>

Dowds, J. Anaerobic Digestion: A Farm Methane Mitigation Strategy for Vermont Dairies. Vermont Climate Collaborative. 2009. Accessed September 13 2011. Available from: http://www.uvm.edu/ vtcc/documents/Farm_Methane_and_Anaerobic_Digestion_Report.pdf

Edelmann W, Engeli H Gradenecker M. Co-digestion of organic solid waste and sludge from sewage treatment. Water Sci Technol 2000; 41(3): 213-221. 
Ekvall T, Assefa G, Bjorklund A, Eriksson O, Finnveden G. What life-cycle assessment does and does not do in assessments of waste management. Waste manage 2007; 27(8): 989-996. doi:10.1016/j.wasman.2007.02.015.

Ekvall,T, Weidema B. System boundaries and input data in consequential life cycle inventory analysis. Int J LCA 2004; 9(3): 161-171. doi:10.1007/BF02994190.

Finnveden G. Methodological aspects of life cycle assessment of integrated solid waste management systems. Resour Conserv Recy 1999; 26: 173-187. doi:10.1016/S09213449(99)00005-1.

Gentil E, Damgaard A, Bhander GS, Hauschild M, Finnveden G, Barlaz M, Thorneloe S, Kaplan PO, Eriksson O, Matsui Y, Ii R, Thomas B, Jones R, Christensen TH. Models for waste life cycle assessment: Review of technical assumptions. Waste Manage 2010; 30(12): 2636-2648. doi:10.1016/j.wasman.2010.06.004.

Gentil EC, Aoustin E, Christensen TH. Greenhouse gas accounting and waste management. Waste Manage Res 2009; 27: 696-706. doi:10.1177/0734242X09346702.

Gentil, EC, Clavreul J, Christensen TH. 2009b. Global Warming Factor of MSW Management in Europe. Waste Manage Res 2009; 27(9): 850-860. doi:10.1177/0734242X09350659.

Gloy, Brent A., and Jonathan B. Dressler. 2010. Financial barriers to the adoption of anaerobic digestion on US livestock operations. Agr Finance Rev 70(2): 157-168. doi:10.1108/00021461011064932.

Graedel, TE. Streamlined Life-Cycle Assessment. Upper Saddle River, NJ: Prentice Hall, 1998.

Hanemann M. California’s new greenhouse gas laws. REEP 2008; 2(1): 114-129. doi: 10.1093/reep/rem030

ISO. Environmental management - Life cycle assessment - Principles and framework European Standard EN ISO 14040. The International Organization for Standardization, Geneva, Switzerland, 2006a.

ISO. Environmental management - Life cycle assessment - Requirements and Guidelines. European Standard EN ISO 14040. The International Organization for Standardization, Geneva, Switzerland, 2006b.

Kirkeby, JT, Hansen TL, Birgisdóttir H, Bhander GS, Hauschild MZ, Christensen TH. Environmental assessment of solid waste systems and technologies: EASEWASTE. Waste Manage Res 2006; 24: 3-15.

Manfredi S, Christensen TH. Environmental assessment of solid waste landfilling technologies by means of LCA-modeling. Waste Manage 2009; 29: 32-43. 
Marnay C, Fisher D, Murtishaw S, Phadke A, Price L, Sathaye J. Estimating carbon dioxide emissions factors for the California electric power sector. Lawrence Berkeley National Laboratory Report 49945, 2002.

Matteson, G. C and Jenkins, B. M. Food and processing residues in California: Resource assessment and potential for power generation. Bioresour Technol 2007; 98(16): 3098-3105. doi:10.1016/j.biortech.2006.10.031.

McCarthy RW, Yang C, Ogden J. Impact of electric-drive vehicles on California's energy system. Institute of Transportation Studies, University of California, Davis, Research Report UCD-ITS-RP-08-24, 2008.

McDougall F, White P, Franke M, Hindle P. Integrated Solid Waste Management: A Life Cycle Inventory. 2nd ed. Oxford; Malden, MA: Blackwell Science, 2001.

McKone, T., Nazaroff, W. W, Berck, P., Auffhammer, M., Lipman, T., Torn, M., Masanet, E., Mishra, U., Lobscheid, A., Santero, N., Barrett, A., Bomberg, M., Fingerman, K., Scown, C., Strogen, B. and Horvath, A. Grand Challenges for Life-cycle Assessment of Biofuels. Environ Sci Technol 2011; 45(5): 1751-1756.

Murray, A., Horvath, A. and Nelson, K. Hybrid Life-cycle Environmental and Cost Inventory of Sewage Sludge Treatment and End-Use Scenarios: A Case Study from China. Environ Sci Techno 2008; 42(9): 3163-3169, http://dx.doi.org/10.1021/es702256w

Pacca, S. and Horvath, A.Greenhouse Gas Emissions from Building and Operating Electric Power Plants in the Upper Colorado River Basin. Environ Sci Technol 2002; 36(14):3194-3200.

Padia T. Personal Communication. Source Reduction and Recycling Director, Stopwaste.org, July 9, 2010.

Rabl A, Benoist A, Dron D, Peuportier B, Spadaro J, Zoughaib A. How to account for $\mathrm{CO}_{2}$ emissions from biomass in an LCA. Int J LCA 2007; 12(5): 281. doi:10.1065/lca2007.06.347.

Riber C, Bhander G, Christensen TH. Environmental assessment of waste incineration in a life cycle perspective (EASEWASTE). Waste Manage Res 2008; 26: 96-103.

Rickerson W, Baker SE and Wheeler M. Renewable gas and California's new feed-in tariff. BioCycle 2008, 49(3): 56

Searchinger TD, Hamburg SP, Melillo J, Chameides W, Havlik P, Kammen DM, Likens GE, et al. Fixing a critical climate accounting error. Science 2009; 326(5952): 527-528. doi:10.1126/science.1178797.

Sosnowski P, Klepacz-Smolka A, Kaczorek K, Ledakowicz S. Kinetic investigations of methane co-fermentation of sewage sludge and organic fraction of municipal solid wastes. Biores Tech 2008; 99(13): 5731-5737. 
Stokes, J. and Horvath, A. Life-cycle assessment of urban water provision: Tool and case study in California.” J Infrastruct Syst 2011;17(1): 15-24.

Stokes, J. and Horvath, A. Supply chain environmental effects of wastewater utilities. Environ Res Lett 2010; 5(1), 014015, http://dx.doi.org/10.1088/1748-9326/5/1/014015

Stokes, J. and Horvath, A. Energy and air emission effects of water supply.” Environ Sci Technol 2009; 43(8): 2680-2687, http://dx.doi.org/10.1021/es801802h

Themelis NJ, Ulloa PA.Methane generation in landfills. Renew Energ 2007; 32: 12431257.

United States Environmental Protection Agency (2006). Solid waste management and greenhouse gases: a lifecycle assessment of emissions and sinks. $3^{\text {rd }}$ edition. Accessed online July 19, 2010: http://epa.gov/climatechange/wycd/waste/SWMGHGreport.html 


\section{Figures}

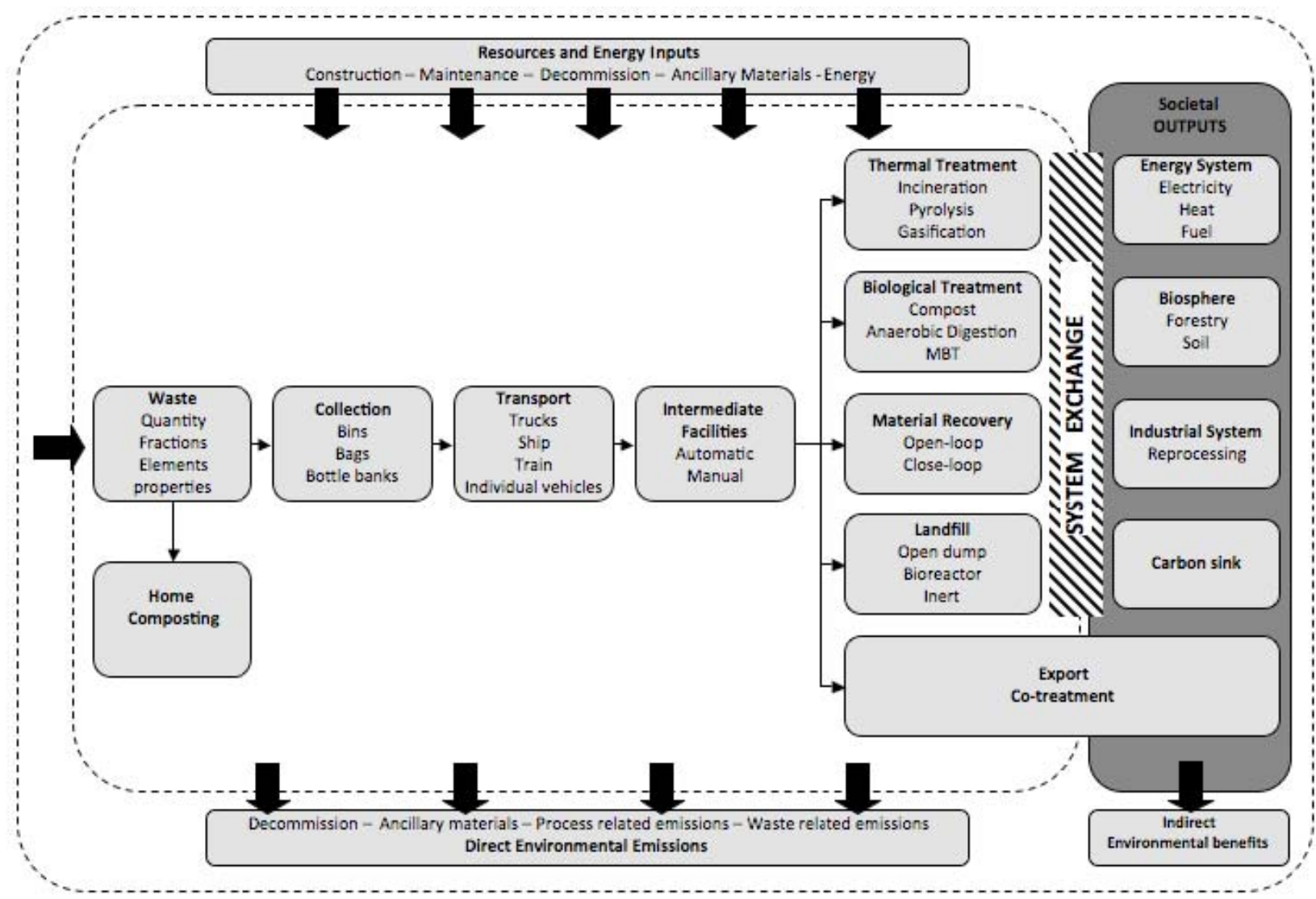

Figure 1 System boundary for LCA of solid waste management system. The dotted line shows the boundary for the waste management system, and the large box shows the boundary for the LCA. Used with permission from Gentil et al., 2010. 
Business As Usual (BAU) / 40\% Reduction

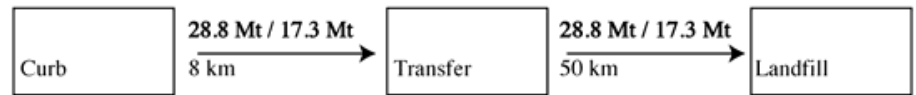

$-\overline{-} \overline{-}-\overline{-}--------$

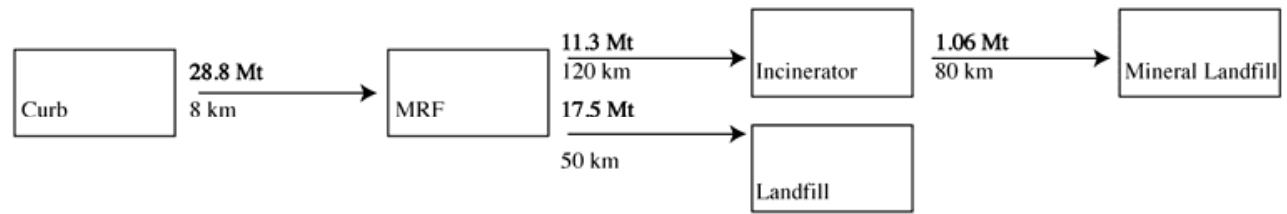

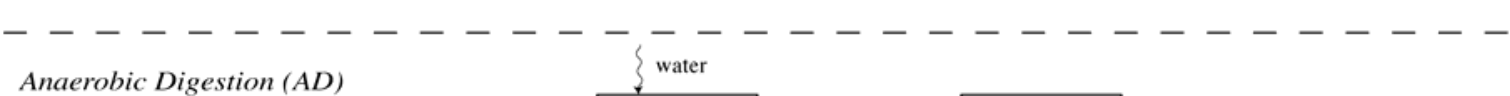

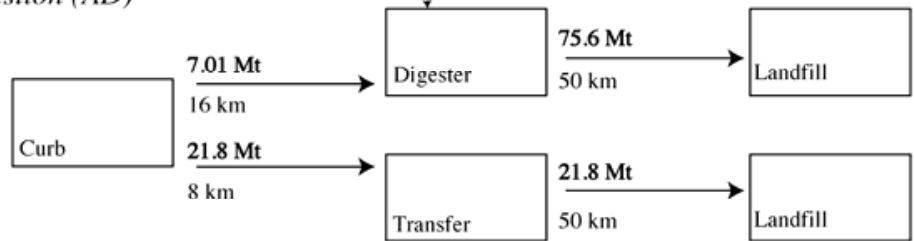

Max Energy

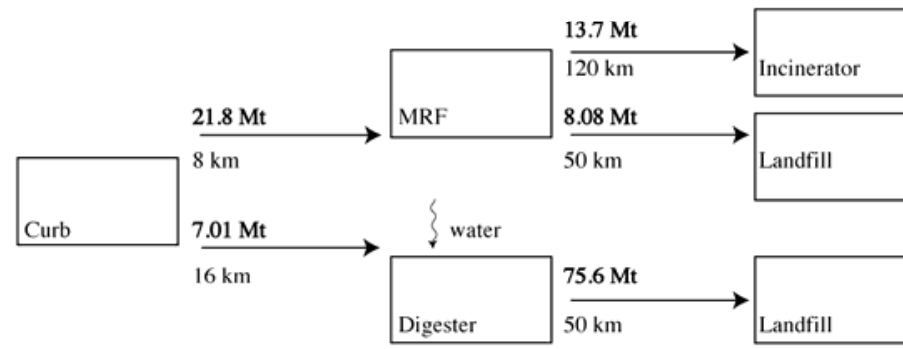

Figure 2 Mass flows (in Mt, million tonnes, CO2-e) and transport distances (in kilometers) for each waste scenario. Incineration and Max Energy scenarios include waste sorting at Material Recovery Facilities, and the other scenarios do not require further sorting, and use transfer stations to move the waste to larger vehicles. 


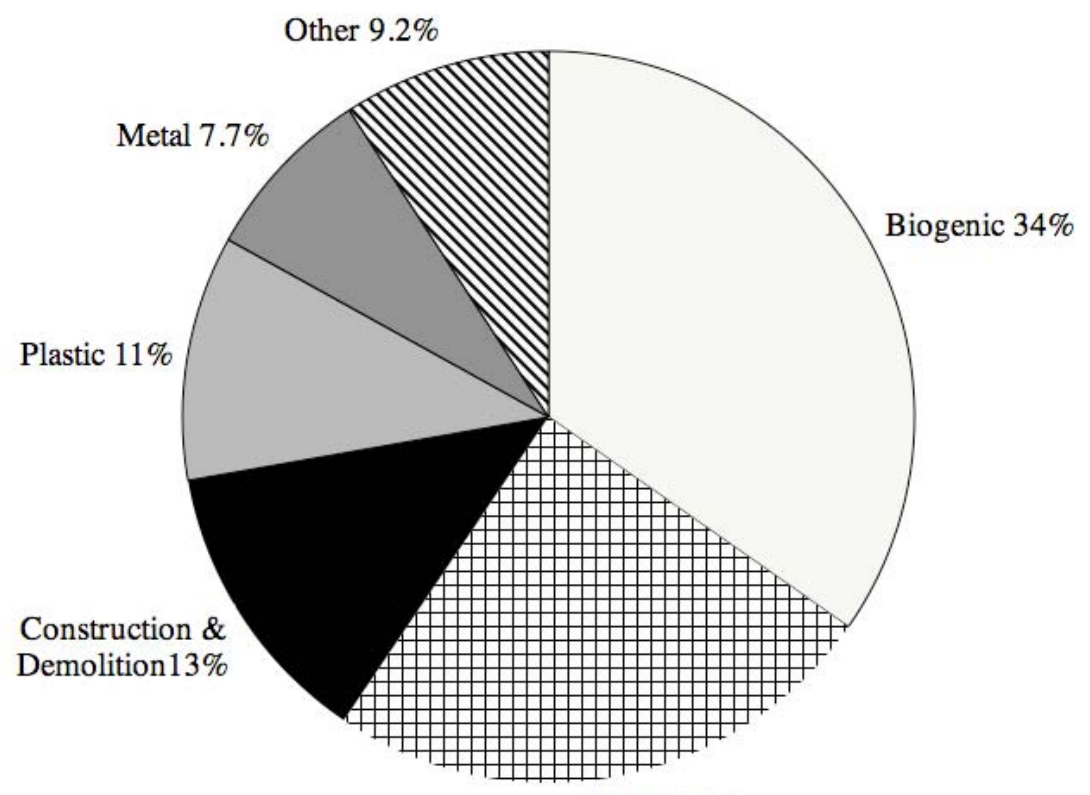

Paper 25\%

Figure 3 Material types in California residential and commercial Municipal Solid Waste, by mass. Source: CIWMB, 2006. “Other” includes glass (2.7\%), electronic (1.4\%), special waste (3.6\%), mixed residue (1.3\%) and household hazardous waste $(0.2 \%)$. Total may not sum to $100 \%$ due to rounding.

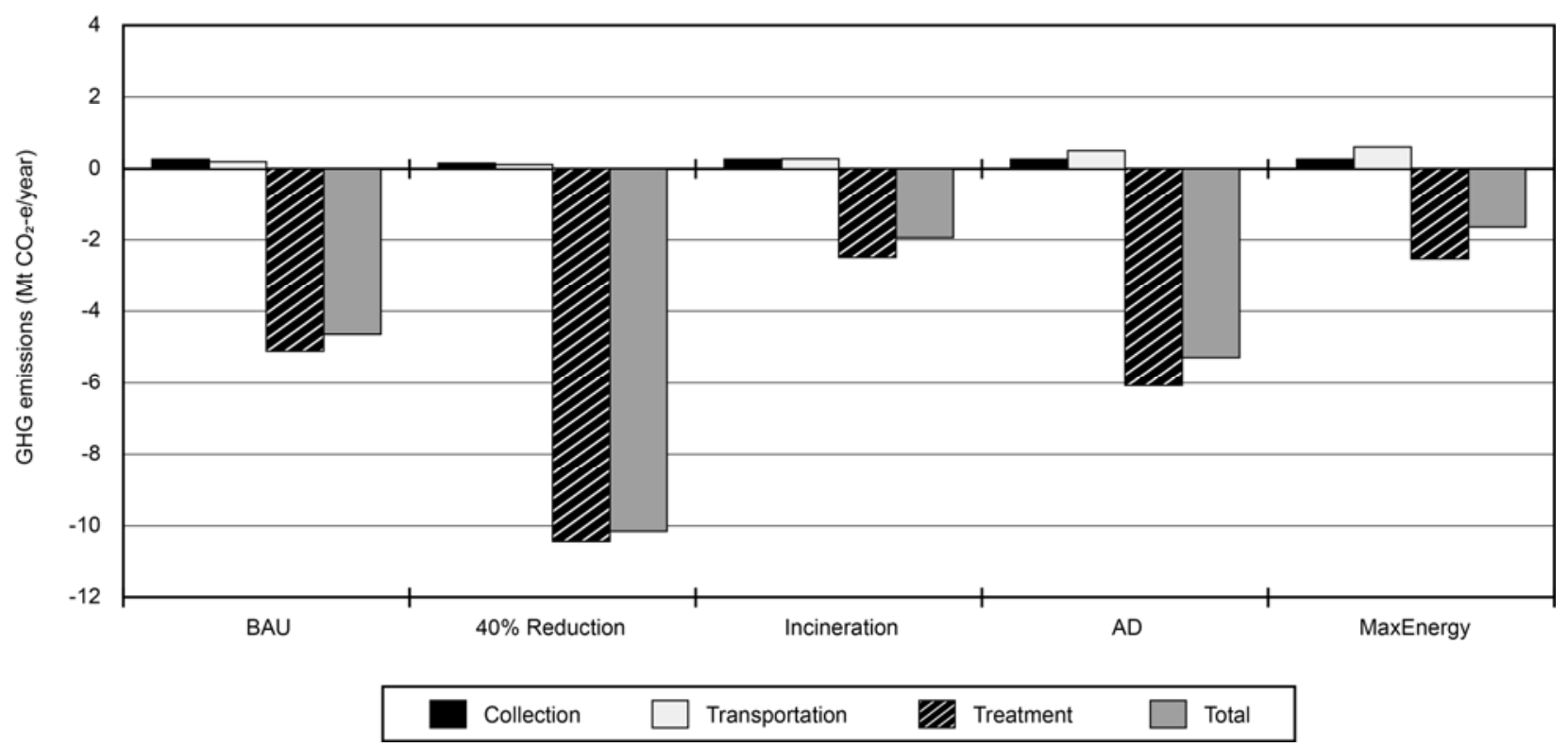

Figure 4 Life-cycle GHG emissions (in Million tonnes CO2-e) from alternative scenarios for managing California's Municipal Solid Waste, calculated using EASEWASTE. 


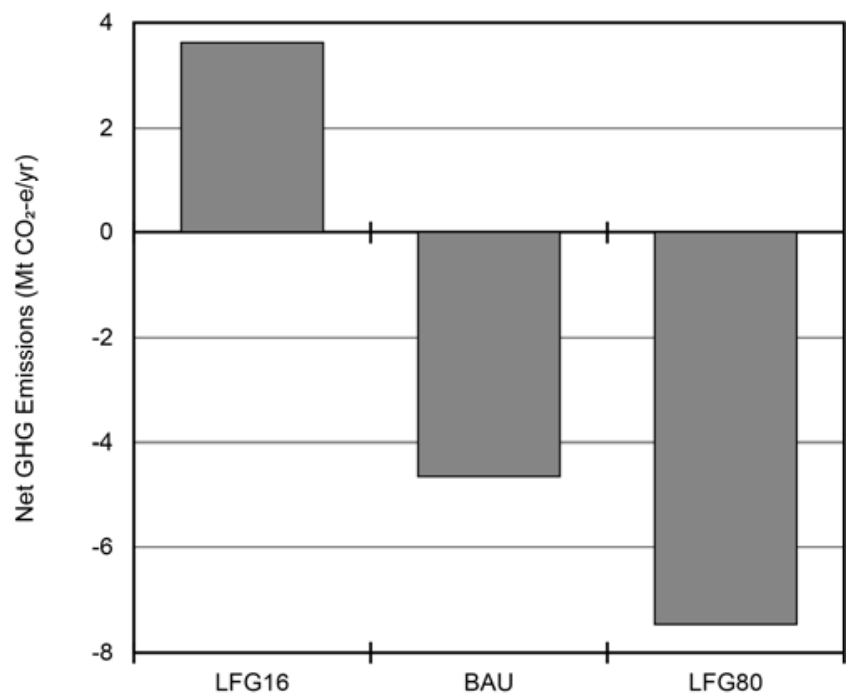

Figure 5 GHG emission sensitivity to landfill gas collection rates, calculated in EASEWASTE, in Million tonnes CO2-e. LFG16 represents a BAU scenario, but with landfills with low gas collection (16\% over 35 years); LFG80 is a BAU scenario with high landfill gas collection (80\% over 35 years). BAU has a landfill gas capture rate of $64 \%$ over 35 years.

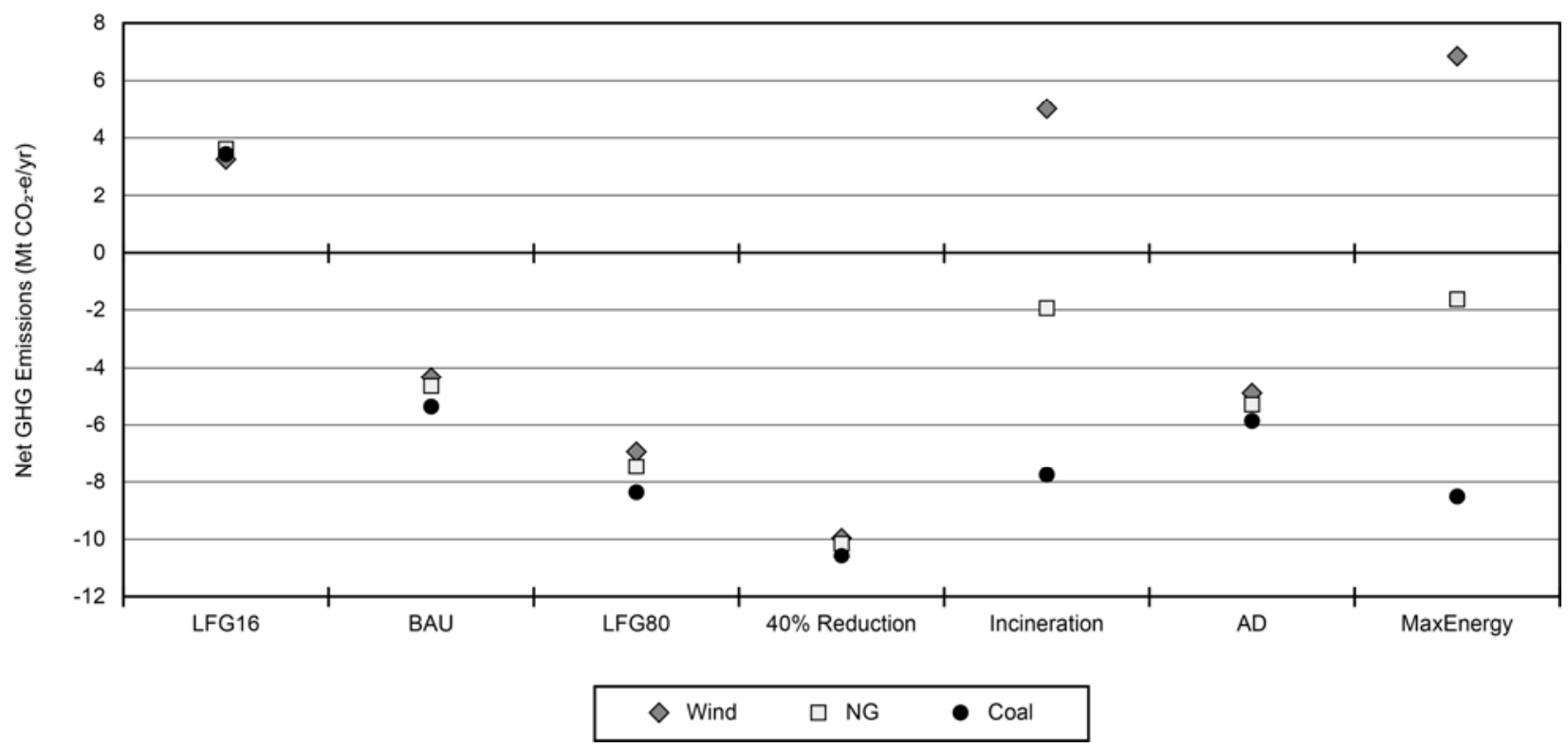

Figure 6 Electricity type displaced by waste-derived electricity affects climate impact (in Million tonnes CO2e) of scenarios for treatment of California's MSW. Calculated using EASEWASTE. 


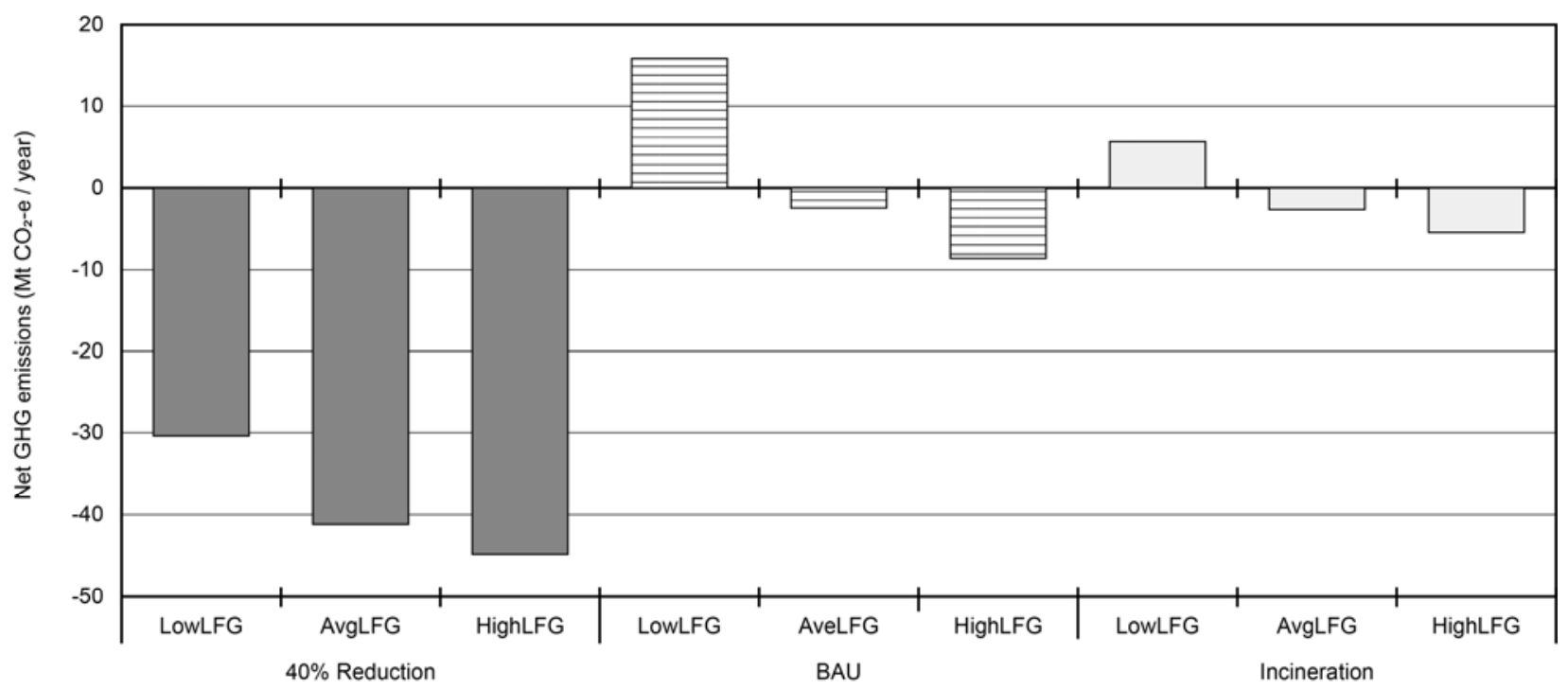

Figure 7 Life-cycle GHG emissions for alternative treatment scenarios for California's MSW, using the US EPA's Waste Reduction Model (WARM), in Million tonnes (Mt) CO2-e.

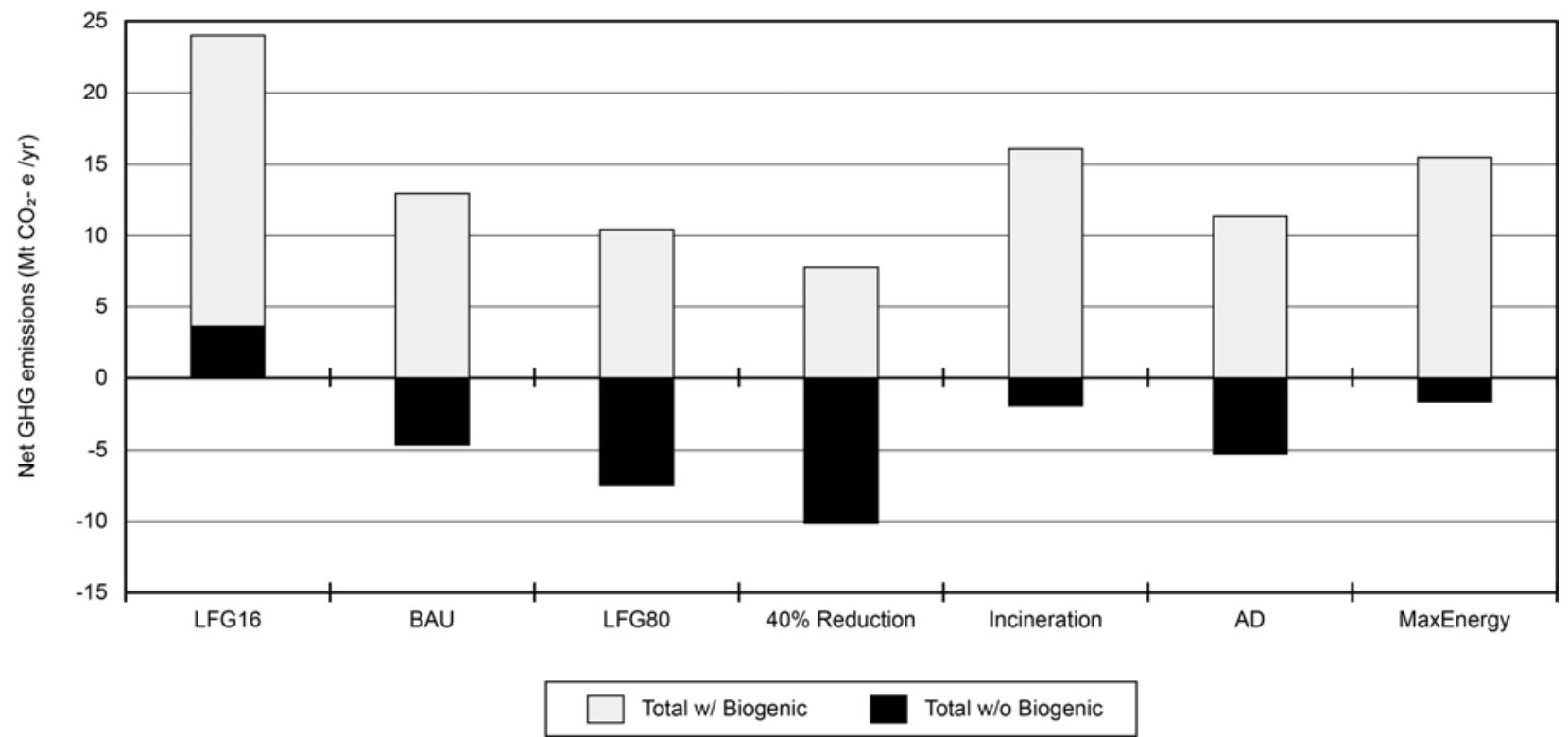

Figure 8 Counting biogenic carbon does not change the ranking of preferred waste treatment scenarios, but does change the net greenhouse gas emissions estimated from each scenario. 